\title{
FUVAC Regimen
}

National Cancer Institute

\section{Source}

National Cancer Institute. FUVAC Regimen. NCI Thesaurus. Code C10083.

A chemotherapy regimen consisting of fluorouracil, vinblastine, doxorubicin, and

cyclophosphamide that may be used in the treatment of breast cancer. 